\title{
ИСПОЛЬЗОВАНИЕ ФАКТОРНОГО АНАЛИЗА ДЛЯ ЭКСПРЕСС- ДИАГНОСТИКИ МИНЕРАЛЬНОГО СОСТАВА ГЕОЛОГИЧЕСКИ СЛОЖНЫХ ОБЪЕКТОВ ПО РЕНТГЕНОДИФРАКЦИОННЫМ ДАННЫМ
}

Козлов Е.Н., Фомина Е.Н.

Геологический институт КНЦ РАН, Апатиты, kozlov_e.n@mail.ru

\begin{abstract}
Аннотация.
В статье представлен новый метод статистического сопоставления минералогических и геохимических данных. На примере карбонатитов Петяйян-Вары (Вуориярви, Кольский регион) показано, что применение этого метода к геологически сложным объектам позволяет 1) экспрессно определить минеральный состав пород на уровне породообразующих и второстепенных минералов; 2) в ряде случаев проследить парагенетические связи; 3) выявить роль каждой из минеральных фаз в распределении петрогенных и редких элементов.
\end{abstract}

\section{Summary.}

The paper presents a new method of statistical comparison of mineralogical and geochemical data. On the example of the Petyayan-Vara carbonatites (Vuorijarvi, Kola region), it is shown that the application of this method to geologically complex objects allows 1) to make an express determination of the mineral composition of rocks (both main and secondary minerals); 2) in some cases to trace paragenetic relations; 3) to identify the role of each mineral phase in the distribution of major and trace elements.

Многие геологи, независимо от сферы их научных интересов, сталкиваются с проблемой сопоставления минералогических и геохимических данных. При отборе геохимических проб геологи стремятся к их максимальной представительности, для чего прибегают к специальным методикам пробоотбора (отбор штуфов «конвертом», сборно-сколковое и бороздовое опробования). Цель всех отмеченных методик - охарактеризовать значительный объём породы. В то же время при минералогических исследованиях, напротив, доминируют локальные методы (микрозонд, LA-ICP-MS и др.), а сами препараты (шлифы, шайбы) представляют двухмерные срезы пород субдюймовой площади. Таким образом, происходит сравнение объектов разного масштаба: геохимические данные характеризуют значительный объём породы, в то время как минералогические - лишь её параметры «в точке», хотя эти параметры и экстраполируются на тот же объём, для которого получена геохимическая информация. Данная экстраполяция не корректна в первую очередь для такситовых пород, к каковым относятся всевозможные метасоматиты, а также многие магматические и метаморфические образования. Предлагаемая нами методика основана на сопоставлении минералогических и геохимических данных, извлечённых из одного и того же объёма вещества, то есть имеющих «единый масштаб».

В качестве источника минералогической информации о породах были 
выбраны рентгеновские дифрактограммы их валовых проб, что базировалось на следующем наборе свойств дифрактограмм:

- порошковая дифракционная картина является индивидуальной характеристикой кристаллического вещества;

- каждая кристаллическая фаза дает всегда одинаковый дифракционный спектр, характеризующийся набором межплоскостных расстояний d(hkl), которые также могут быть представлены в величинах угла $2 \Theta$, и соответствующих интенсивностей линий I(hkl), присущих только данной кристаллической фазе;

- рентгенодифракционный спектр от смеси индивидуальных фаз является суперпозицией их дифракционных спектров;

- соотношение интенсивностей присутствующих в конкретном образце кристаллических фаз пропорционально содержанию фаз в нём.

Именно на этих свойствах основываются качественные и количественные методы рентгенофазового анализа $[1,2]$. Для нас важным также является то, что интенсивности отдельных пиков каждого минерала пропорциональны друг другу, а значит скоррелированы. Это позволило при разделении скрытой в дифрактограммах информации, относящейся к различным минеральным фазам, в качестве «сита» использовать факторный анализ (ФА). Данный вид статистической обработки ориентирован именно на выделение скоррелированных составляющих данных.

Подробно описания различных методик ФА изложены во многих публикациях, в том числе в свете их применения к геологическим объектам (например, [3, 4]). Мы приведём лишь необходимые общие сведения. Алгоритмы факторного анализа сводятся к понижению размерности признакового пространства за счёт определения небольшого числа скрытых факторов, изменчивость которых объясняется изменчивостью всех наблюдаемых признаков (переменных), связанных с каждым из изученных объектов (в нашем случае - проб). Сами факторы являются линейной комбинацией наблюдаемых переменных, коррелируемых между собой. Необходимо отдельно отметить важное понятие «факторная нагрузка» (в тексте $-\mathrm{r}^{\mathrm{FA}}$ ), применяемое для описания роли признака в формировании определенного фактора. Это - коэффициент корреляции между переменной и фактором, и для оценки его статистической значимости применяются стандартные тесты.

Схематично процедура выделения факторов описывается следующим образом. Первый из факторов подбирается из того условия, чтобы после его исключения из всех наблюдаемых переменных коэффициенты корреляций между всеми парами наблюдаемых переменных были минимальными. Затем процесс повторяется для переменных с исключенным влиянием уже выявленного фактора (факторов). Для упрощения интерпретации результатов на заключительном этапе обычно прибегают к процедуре ортогонального или косоугольного вращения факторов, задача которого состоит в достижении так называемой простой структуры данных. Грубо говоря, структу- 
ра считается простой в том случае, если большинство факторных нагрузок каждого «повернутого» фактора близки к нулю, и лишь некоторые из них относительно велики. Цель вращения заключается в представлении каждой исходной переменной лишь несколькими (в идеальном варианте - одним) факторами.

В основу исследования легла коллекция из 43 образцов редкоземельных карбонатитов поля Петяйян-Вара (девонский щелочно-ультраосновный карбонатитовый массив Вуориярви). Эти породы, образовавшиеся в ходе нескольких наложенных метасоматических событий [5], характеризуются структурно-конституционной такситовой текстурой и чрезвычайно сложны для петрографического изучения.

Каждый образец помимо рентгеновских данных (3351 переменная) был дополнительно охарактеризован содержаниями петрогенных и редких элементов (еще 47 переменных). В связи с тем, что объём информации, сосредоточенный в «геохимических переменных» составил порядка 1 \% от всего объёма первичных данных, они не оказали какого-либо заметного влияния на структуру выделенных факторов. Это было подтверждено численным экспериментом: графики факторных нагрузок факторов, выделенных лишь по дифрактограммам, аналогичны таковым для факторов с геохимическим «прицепом». В то же время именно этот приём позволил связать изначально «минералогические» факторы с геохимией. Факторы были рассчитаны в программном пакете IBM SPSS Statistics v.23.

Факторный анализ выделил более 3 тысяч факторов, из которых первые 42 объясняют 100.000 \% совокупной дисперсии переменных. Мы не интерпретировали все факторы, поскольку, учитывая факторные нагрузки «геохимических» переменных, только 14 из 42 факторов оказали статистически значимое влияние на распределение петрогенных (табл. 1) и большинства редких (табл. 2) элементов. Поэтому изучались только эти 14 факторов. Наше исследование показало, что за данные факторы «отвечают» следующие минералы (в порядке убывания объясненной фактором дисперсии): барит, доломит, кальцит, анкилит-(Ce), микроклин, флогопит, фтор-апатит, кварц, стронцианит, гётит, альбит, эгирин, гидроксилбастнезит-(Cе) и анкерит (рис. 1).

Основанием для интерпретации послужило то, что графики их факторных нагрузок имеют отчётливое сходство с рентгеновскими спектрами соответствующих минералов из специализированных баз данных (например, ICDD PDF-2, AMCSD, RRUFF). Проиллюстрируем это на примере фактора фтор-апатита (рис. 2), соответствующего спектру (7) на рис. 1. Смещение положений пиков графиков факторных нагрузок $\mathrm{r}^{\mathrm{FA}}$ от пиков на дифрактограммах стандартов соответствующих минералов не превышает $\pm 0.1^{\circ}$, хотя графики и отличаются морфологией из-за различий интенсивности этих пиков. Принимая это во внимание, мы определили минеральные фазы, ответственные за каждый фактор, путём поиска их в рентгеновских базах данных, 


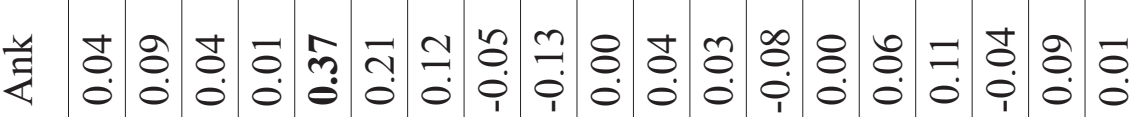
悬

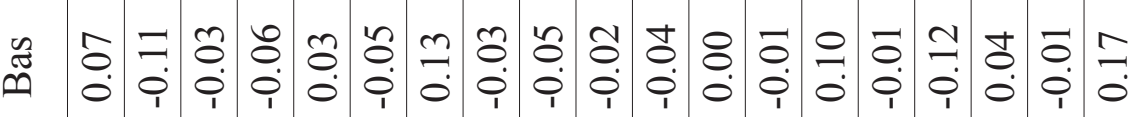

चึ

㦴泀

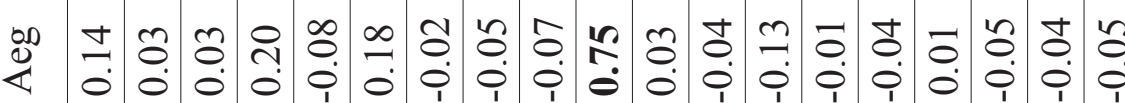

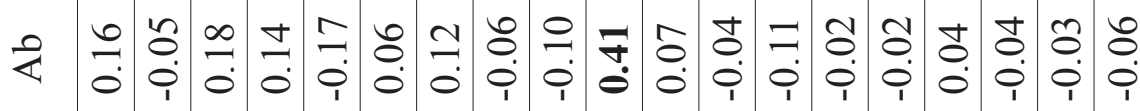

$\div<$

苗

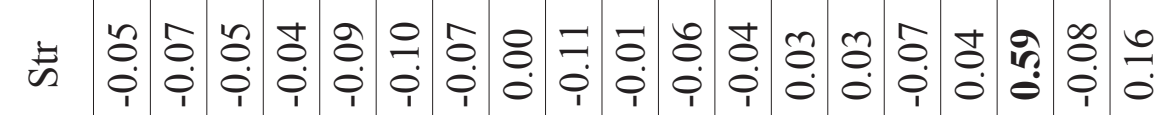

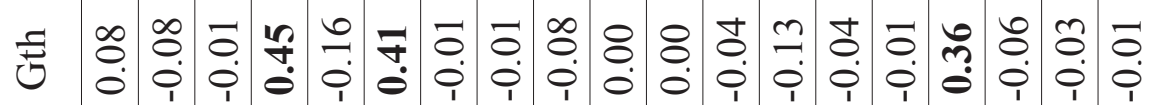
: त्ष

I

苞苞

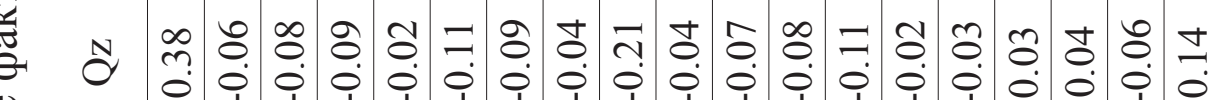

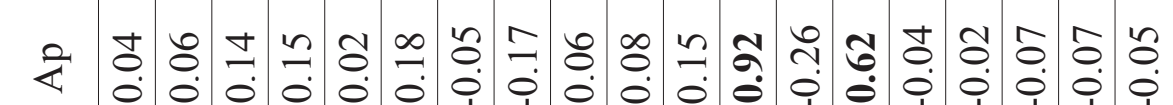

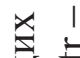

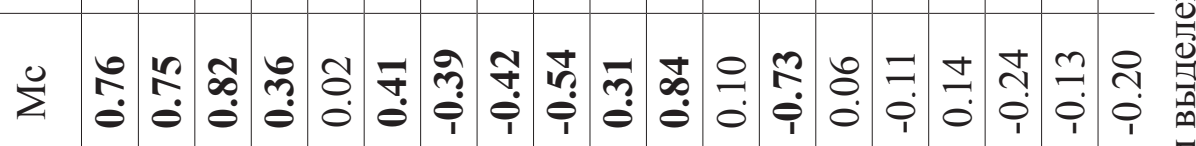

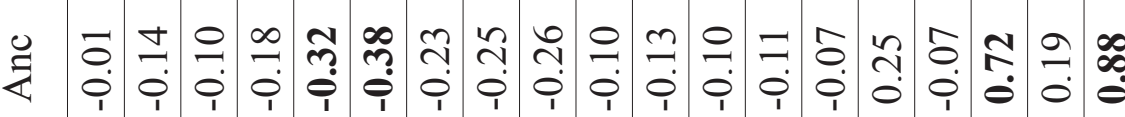

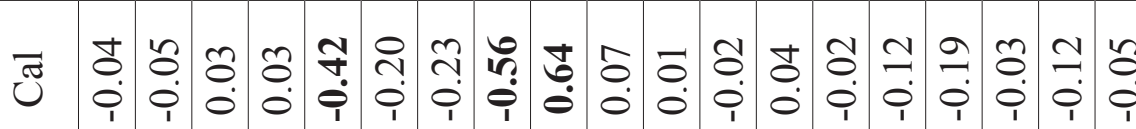

官

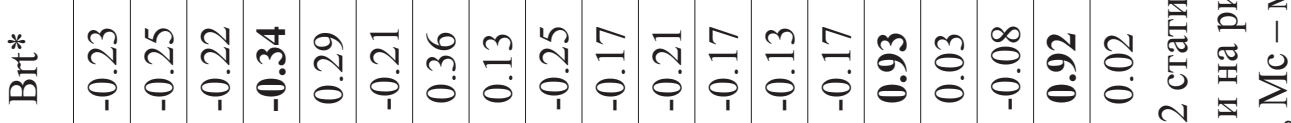

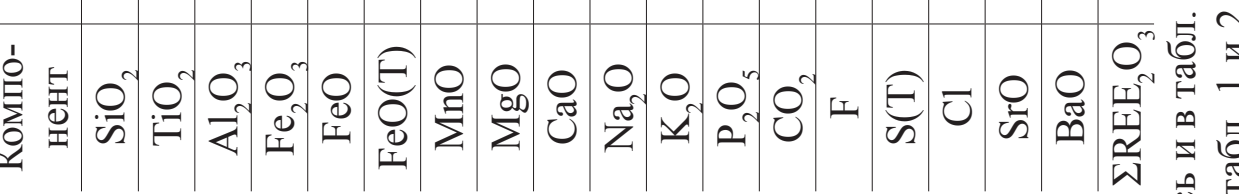




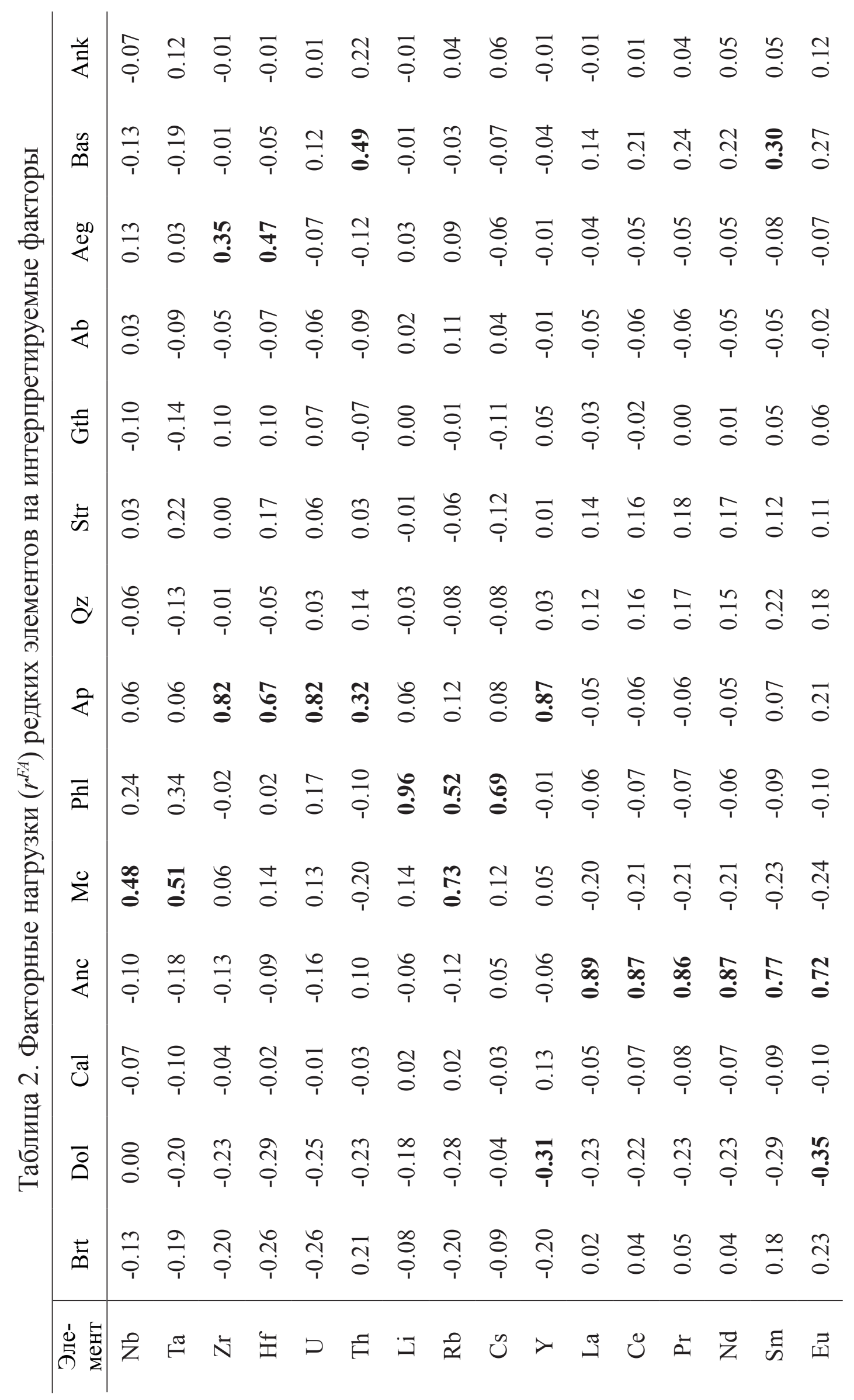




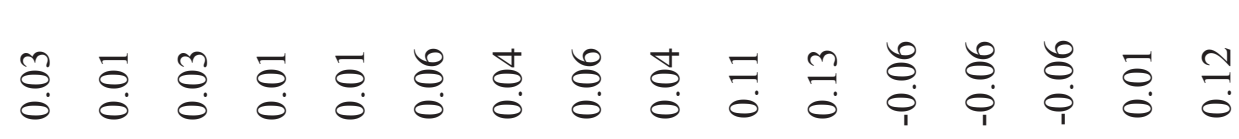

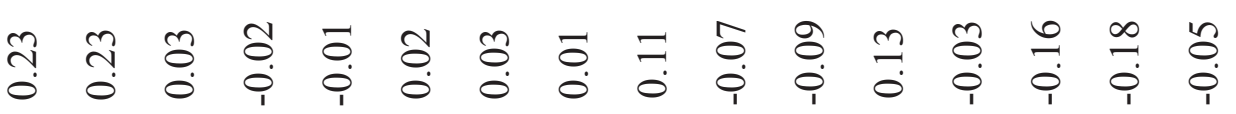

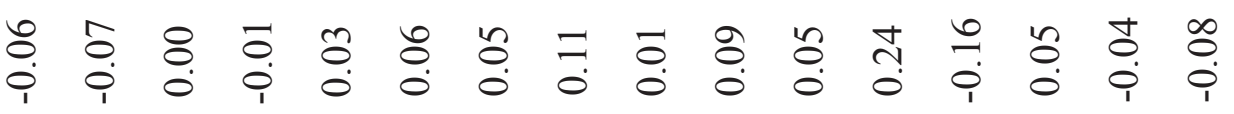

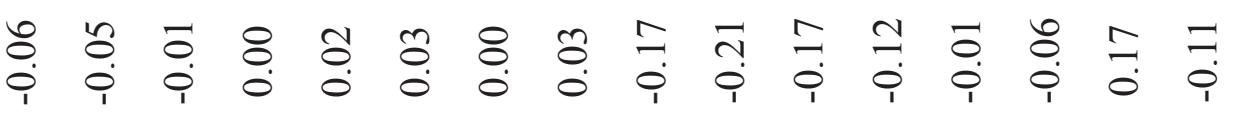

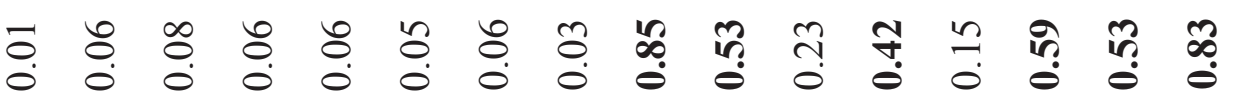

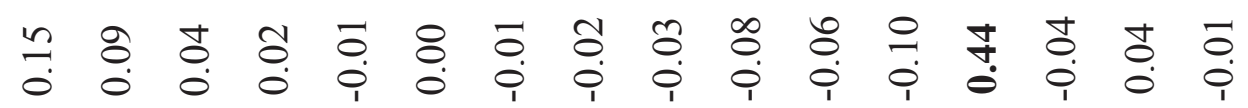

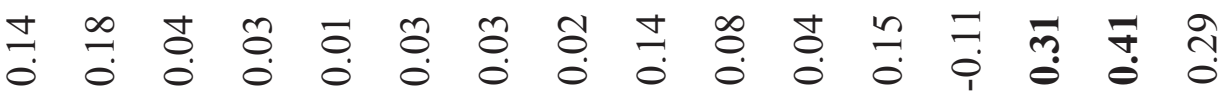

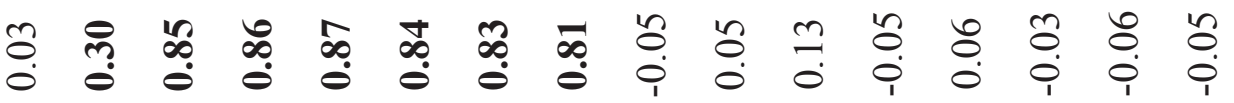

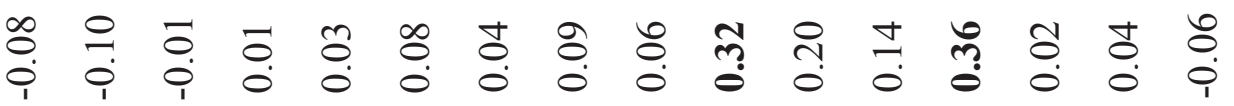

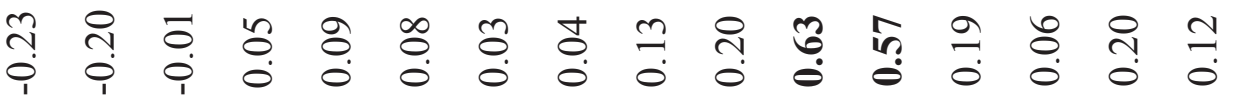

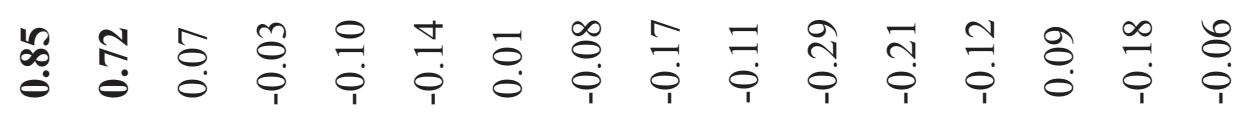

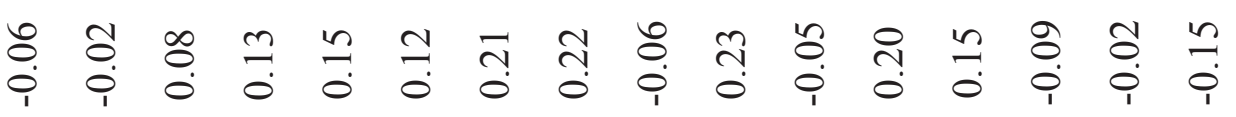

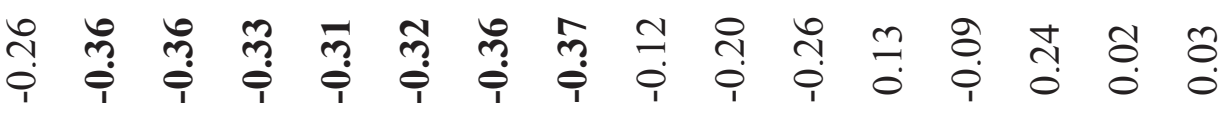

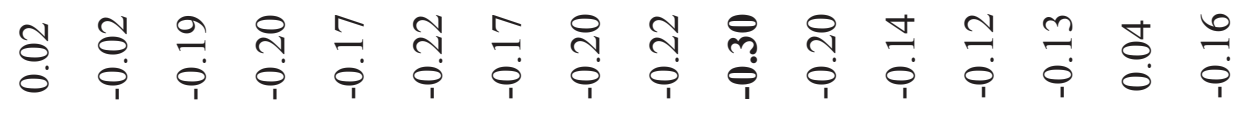

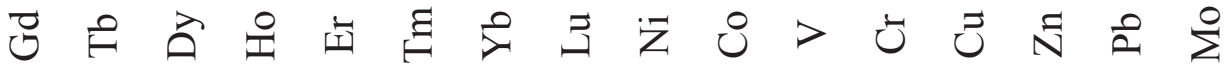


ориентируясь по положениям пиков на графиках факторных нагрузок.

Согласно проведённому исследованию, все 14 минералов«факторообразо-вателей» по содержаниям являются либо главными, либо второстепенными, по меньшей мере, в одном из образцов изученной коллекции. Таким образом, приведённый выше перечень фаз почти полностью соответствует набору породообразующих и вторичных минералов в образцах коллекции Петяйян-Вары. Единственными исключениями стали оксиды титана, которые не образуют своего собственного фактора, хотя этими минералами и богаты некоторые разновидности карбонатитов Петяйян-Вары. Для каждого образца были рассчитаны значения факторов, максимальные величины которых точно «предсказали», какие пробы наиболее насыщены тем или иным из рассматриваемых минералов. Это ещё раз подтвердило то, что выделенные факторы напрямую связаны с минеральным составом пород. Таким образом, в предлагаемом нами подходе отсутствует одна из основных причин критики факторного анализа, заключающаяся в сложности интерпретации получаемых результатов.

Каждый рассматриваемый фактор отмечен значимыми нагрузками одного или нескольких химических элементов, часто достигающими величины 0.8 и более. Эти «элементы-индикаторы» в большинстве своем либо входят в кристаллохимическую формулу соответствующего минерала, либо являются его типичными примесями. Такова, например, природа высоких нагрузок бария (0.92) и серы (0.93) на фактор барита, или лития (0.96) на фактор биотита. С одной стороны, подобные высокие нагрузки позволяют существенно облегчить определение минерала, отвечающего фактору. В то же время концентрации самих этих элементов являются геохимическими маркерами, позволяющими произвести грубую оценку содержания минерала в породе, что подтверждено петрографическим исследованием. Например, в тех карбонатитах, где было определено менее 10 ppm Li, слюда отсутствовала. В породах, где Li более 10 ppm, объёмные содержания слюды растут пропорционально концентрациям этого элемента и достигают своего максимума в образце, максимально обогащённом литием (450 ppm). Интенсивности рефлексов минерала в дифрактограмме валовой пробы зависят от содержания этого минерала. Поэтому высокая факторная нагрузка элементов-индикаторов свидетельствует только о том, что концентрации таких элементов пропорциональны содержаниям соответствующих минералов-«факторообразователей», что и продемонстрировано на примеpe Li и биотита.

В этом свете, однако, высокие нагрузки циркония $(0.82)$ и гафния $(0.67)$ на фактор апатита, а также титана (0.70), ниобия (0.48) и тантала $(0.51)$ - на микроклин и ряд других не находят объяснения с позиции кристаллохимии. Кроме того, тщательный анализ графиков $r^{F A}$ показал, что, несмотря на высокое разрешение предлагаемого метода, позволившего отделить Fе-доломит 

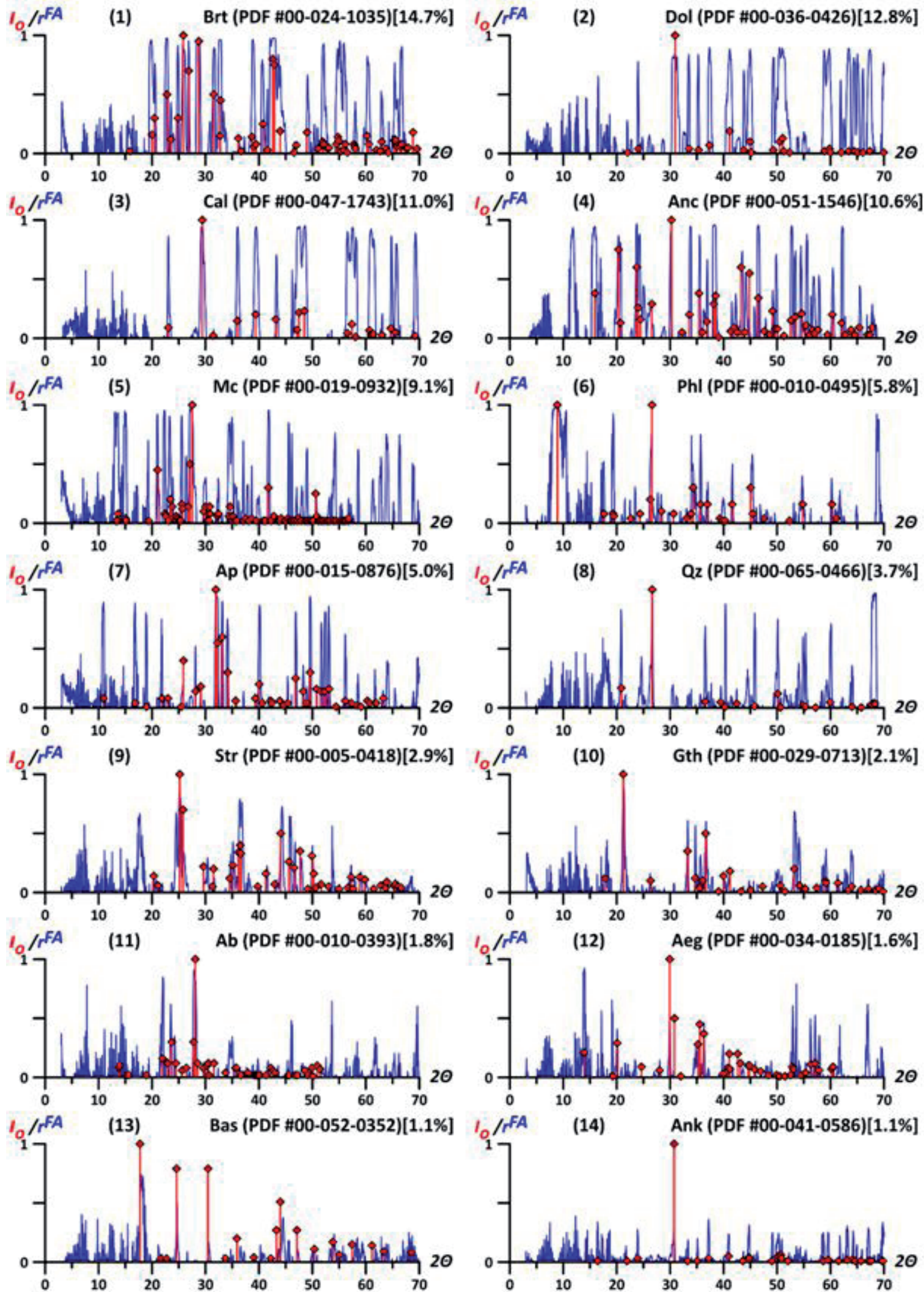

Рис. 1. Сопоставление графиков факторных нагрузок ( $\left.r^{F A}\right)$ (синие линии; отрицательные факторные нагрузки для упрощения исключены) с позициями пиков на эталонных дифрактограммах минералов-«факторообразователей» (красные столбики; $I_{O}$ - относительная интенсивность, максимальныій пик приравнен к 1). В квадратных скобках - доля объясненной фактором дисперсии. Эталонные дифракиионные картины минералов взяты из базы данных ICDD PDF-2, в круглых скобках указаны номера использованных PDF-карточек. 
от анкерита (эти фазы имеют чрезвычайно близкие положения всех линий), не во всех случаях сепарация произошла «идеально». Так, на графике факторных нагрузок стронцианита присутствуют интенсивные пики на углах $17.66^{\circ}$ и $24.52^{\circ}$ (см. график 9 на рис. 1), не характерные для дифрактограмм этого минерала. В то же время не менее яркие пики занимают сходное положение $\left(17.98^{\circ}\right.$ и $\left.24.68^{\circ}\right)$ на графике $r^{F A}$ гидроксилбастнезита (см. график 13 на рис. 1). Они отвечают самым выраженным рефлексам дифрактораммы от плоскостей (002) и (300) гидроксилбастнезита-(Се). Это объясняется тем, что в тесной ассоциации со стронцианитом сосуществует ещё одна генерация бастнезита, по петрографическим данным более ранняя, чем та, что даёт собственный фактор. Именно её присутствие отражают рассмотренные «паразитические» пики графика $r^{F A}$ стронцианита, смещение которых в сторону меньших значений $2 \Theta$, вероятнее всего, связано с тем, что это - бастнезит(Ce), в состав которого входит не ОН группа, а фтор.

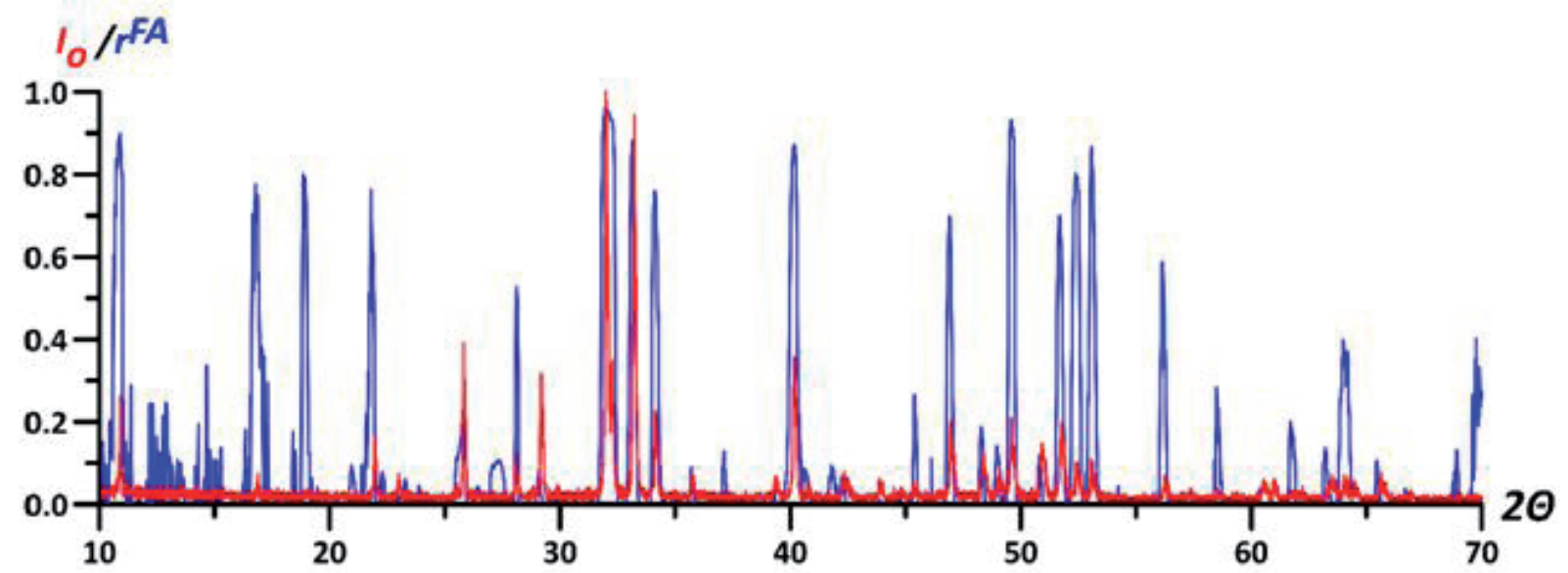

Puс. 2. Сопоставление рентгеновской дифрактограммы фторапатита из базы RRUFF (анализ R050529, красная линия; I - относительная интенсивность, максимальный пик приравнен к 1) с графиком факторных нагрузок ( $\left.r^{F A}\right)$ на фактор апатита (синяя линия, отрищательные факторные нагрузки для упрощения исключень) в диапазоне $2 \Theta$ от $10^{\circ}$ до $70^{\circ}$.

Мы предполагаем, что причина появления кристаллохимически «запрещённых» высоких нагрузок на геохимические переменные и «паразитических» пиков едина. Как было показано, извлеченные факторы, по крайней мере, в некоторых случаях, являются выражением не одного, а нескольких минералов. Такая комбинация возможна только тогда, когда пики отдельно взятых рентгенодифракционных спектров этих минералов взамопропорциональны. Это свидетельствует о том, что «объединённые» в один фактор фазы возникли в субстехиометрических количествах во время единой реакции минералообразования и являются парагенными.

Кристаллохимически «запрещённые» высокие факторные нагрузки циркония и гафния на фактор фтор-апатита объясняются с той же позиции. Концентратор указанных элементов - циркон, но его содержание настолько мало, что содержание Zr в породах не превышает 320 ppm. Из-за этого на 
дифрактограммах нет ни цирконовых рефлексов, ни его «паразитических» пиков на графике $r^{F A}$ фактора фторапатита. Несмотря на это, чрезвычайно высокие значения $r^{F A}$ для Zr и Hf непосредственно указывают на парагенетическую связь этих минералов. Не меньший интерес представляет появление значительных факторных нагрузок Ti, Nb и Та на микроклиновый и (в меньшей степени) флогопитовый факторы (см. табл. 1 и 2) при отсутствии факторов собственно титановых минералов. Как было установлено, титан, ниобий и тантал в карбонатитах Петяйян-Вары сконцентрированы главным образом в богатом $\mathrm{Nb}$ бруките, тесно ассоциирующем с микроклином [5]. Наиболее интенсивные пики дифрактограммы брукита совпадают с пиками микроклина, что, по всей видимости, и не позволяет различить на факторе последнего «пиков-паразитов» брукита. Флогопит же сам оказался концентратором титана.

Таким образом, «неидеальное» разделение минералов хотя и усложняет интерпретацию, но также даёт дополнительную информацию о процессах минералообразования и парагенетических связях.

Анализ факторных нагрузок «геохимических переменных» позволил оценить роль каждого из выявленных минералов в распределении петрогенных и редких элементов. Например, установлено, что в исследованной представительной коллекции проб основной объём $\mathrm{Sr}$ и REE содержится в анкилите-(Ce), а не в стронцианите или гидроксилбастнезите-(Ce); главный концентратор Si не кварц, а микроклин; за распределение $\mathrm{Na}$ в равной мере отвечают альбит и эгирин и другие сходные нюансы распределения петрогенных и редких элементов. Все эти выводы также были подтверждены «классическими» лабораторными методами.

Работа выполнена в Геологическом институте КНЦ РАН в рамках тем НИР № 023 1-2015-0007 и № 0231-2015-0009 при финансовой поддержке Российского ФондаФундаментальных Исследований (Проект № 18-35-00068).

\section{Список литературы}

1. Jenkins R., Snyder R.L. Introduction to X-ray Powder Diffractometry / ed. Winefordner J.D. Hoboken, NJ, USA: John Wiley \& Sons, Inc. 1996. DOI: $10.1002 / 9781118520994$

2. Klug H.P., Alexander L.E. X-ray diffraction procedures for polycrystalline and amorphous materials. New York: John Wiley \& Sons. 1974. 966 p.

3. Jöreskog K.G., Klovan J.E., Reyment R.A. Geological factor analysis. Amsterdam: Elsevier Scientific Pub. Co. 1976. 178 p.

4. Le Maitre R.W. Numerical petrology : statistical interpretation of geochemical data. Amsterdam: Elsevier Scientific Pub. Co, 1982. 281 p.

5. Kozlov E., Fomina E., Sidorov M., Shilovskikh V. Ti-Nb Mineralization of Late Carbonatites and Role of Fluids in Its Formation: Petyayan-Vara Rare-Earth Carbonatites (Vuoriyarvi Massif, Russia) // Geosciences. 2018. Vol. 8. № 8. P. 281. DOI: $10.3390 /$ geosciences 8080281 